Article

\title{
Impact of Intake and Exhaust Ducts on the Recovery Efficiency of Heat Recovery Ventilation Systems
}

\author{
Tom Marsik ${ }^{1,2,3, *}$, Riley Bickford ${ }^{1,2,4}$, Conor Dennehy ${ }^{2,5}$, Robbin Garber-Slaght ${ }^{2,5}\left(\mathbb{D}\right.$ and Jeremy Kasper ${ }^{1}$ (D) \\ 1 Alaska Center for Energy and Power, University of Alaska Fairbanks, Fairbanks, AK 99775, USA; \\ rjbickford@alaska.edu (R.B.); jlkasper@alaska.edu (J.K.) \\ 2 Cold Climate Housing Research Center, Fairbanks, AK 99775, USA; conor.dennehy@nrel.gov (C.D.); \\ robbin.garberslaght@nrel.gov (R.G.-S.) \\ 3 Bristol Bay Campus, University of Alaska Fairbanks, Dillingham, AK 99576, USA \\ 4 Department of Mechanical Engineering, University of Alaska Fairbanks, Fairbanks, AK 99775, USA \\ 5 National Renewable Energy Laboratory, Golden, CO 80401, USA \\ * Correspondence: tmarsik@alaska.edu
}

Citation: Marsik, T.; Bickford, R.; Dennehy, C.; Garber-Slaght, R.;

Kasper, J. Impact of Intake and Exhaust Ducts on the Recovery Efficiency of Heat Recovery Ventilation Systems. Energies 2021, 14, 351. https:// doi.org/10.3390/ en14020351

Received: 17 November 2020 Accepted: 5 January 2021 Published: 10 January 2021

Publisher's Note: MDPI stays neutral with regard to jurisdictional clai$\mathrm{ms}$ in published maps and institutional affiliations.

Copyright: $\odot 2021$ by the authors. Licensee MDPI, Basel, Switzerland. This article is an open access article distributed under the terms and conditions of the Creative Commons Attribution (CC BY) license (https:// creativecommons.org/licenses/by/ $4.0 /)$.

\begin{abstract}
The heat recovery efficiency of ventilation systems utilizing heat recovery ventilators (HRVs) depends not only on the heat recovery efficiency of the HRV units themselves but also on the intake and exhaust ducts that connect the HRV units to the outside environment. However, these ducts are often neglected in heat loss calculations, as their impact on the overall heat recovery efficiency of HRV systems is often not understood and, to the knowledge of the authors, a mathematical model for the overall heat recovery efficiency of HRV systems that accounts for these ducts has not been published. In this research, a mathematical model for the overall heat recovery efficiency of HRV systems that accounts for the intake and exhaust ducts was derived and validated using real-life data. The model-predicted decrease in heat recovery efficiency due to the ducts was in reasonable agreement (relative error within 20\%) with the real-life measurements. The results suggest that utilizing this model allows for more correct ventilation heat loss calculations compared to using the heat recovery efficiency of the HRV unit alone, but more field studies are needed to verify the accuracy of this model in a wide range of applications.
\end{abstract}

Keywords: heat recovery ventilator (HRV); recovery efficiency; ducts

\section{Introduction}

The energy used by buildings accounts for over $40 \%$ of total primary energy consumption in the United States and the EU [1]. Reducing the energy consumption of buildings represents an opportunity for cost savings, as well as reducing the societal and environmental impacts associated with the current energy practices [2-4]. One of the options for saving energy in buildings in colder climates is to utilize HRVs instead of traditional ventilation systems that exchange air with no heat recovery.

HRVs reduce the heat loss associated with ventilation by recovering a portion of the heat in the warm, stale air going out and transferring it into the fresh, cold air coming in. The heat recovery efficiency, in general, is defined as the amount of heat recovered relative to the heat that would have been lost due to ventilation if the same amount of air exchange happened without heat recovery. While adhering to this general principle, the specific interpretation of the heat recovery efficiency definition varies throughout the literature to some degree. For example, some authors assume the reference scenario to be natural ventilation, which means the heat loss is directly proportional to the temperature difference between the inside and outside of the building [5,6]. Others assume the reference scenario to be mechanical ventilation with no heat recovery, which means the heat loss can be higher than in the natural ventilation case due to the exhaust air stream being warmed up above the interior building temperature by the heat rejected from the exhaust fans $[7,8]$. 
Regardless of the specific definition used, the resulting values of the heat recovery efficiency for a specific system are typically similar because those definitions that use mechanical ventilation as a reference scenario also account for the fact that some of the heat rejected by the exhaust fans into the air stream is recovered and transferred into the supply air stream [7]. As seen in the Materials and Methods section below, the definition used in our research was one based on the natural ventilation as a reference scenario, as it can be most directly used to calculate the heat loss from a building due to ventilation, which was the focus of our research. Furthermore, our research dealt with sensible heat recovery efficiency only; it did not deal with total heat recovery efficiency. Total heat recovery efficiency considers both sensible heat and latent heat and is used for energy recovery ventilators (ERVs) when utilized in air-conditioned buildings. ERVs transfer moisture, in addition to transferring heat, and are particularly beneficial in hot, humid climates [9].

Several studies have looked at the heat recovery efficiency of HRVs. An early evaluation of HRV technology from circa 1980 found an efficiency of almost 50\% [10]. The same study looked at the effects of fan power consumption and heat conduction through the case of the device on the calculated HRV efficiency. An investigation of the performance of HRVs in China looked at the effect of adding air filters [6]. It found that adding air filters increases the heat recovery efficiency while reducing the airflow. A study of an HRV in the Canadian Arctic showed a significant decrease in heat recovery efficiency with the use of preheaters to prevent frost build-up [8]. The issue of preheaters to prevent frost build-up was also evaluated in Fairbanks, Alaska [11]. In this case, the authors concluded that while the overall energy use was higher, such systems can satisfy ventilation standards, even in very cold temperatures. Systems that rely on recirculation defrosting can have significantly reduced effective ventilation rates in contrast to systems that utilize preheaters. Another study looked at the energy performance of HRV-equipped residences in Fairbanks, Alaska [12]. Theoretical evaluations in that study showed that despite the use of an HRV with a 70\% heat recovery efficiency, the actual savings in energy costs associated with ventilation, as compared to a naturally ventilated building with the same total ventilation rate, were only about 55\%. This was due to the energy needed for the HRV fans, as well as the fact that even in the HRV-equipped residence, some air still infiltrated the building envelope with no heat recovery. The study that is perhaps the most relevant to our research is one that looked at the impact of running a supply air distribution, as well as return air ductwork through unconditioned or semi-conditioned spaces [13]; it found that the heat recovery efficiency of an HRV system can drop from $80 \%$ to less than $50 \%$ if there is ductwork leakage and the thermal resistance is poor. Note that the supply air distribution ductwork is the distribution network that distributes the outside air after it has been warmed up in the HRV unit. If this ductwork is run through unconditioned space, the air in the ductwork can cool down, reducing the effect of the HRV unit that warmed it up.

To our knowledge, there is no published study on the impact of the intake and exhaust ducts on the heat recovery efficiency of HRV systems. In cold climates, HRV units are installed in conditioned space. In part, this is to allow for condensate drainage from the unit. The intake duct connects the HRV unit to the outside fresh air. The intake duct is insulated because it passes through conditioned space and the air inside the duct is cold, while the surrounding, conditioned air is warm. Since the insulating capabilities are finite, some heat from the conditioned space is transferred through the insulation into the cold air in the duct. Because of this, when the cold supply air in the duct reaches the HRV unit itself, it is warmer than the outside air and has a reduced ability to extract the heat from the warm stale air flowing out through the heat exchanger. This lowers the heat recovery efficiency. The exhaust duct also connects the HRV unit to the outside. The warm, stale air going out first passes through the HRV unit before it reaches the exhaust duct. A portion of the heat in the warm stale air is recovered in the HRV unit (transferred into the fresh, cold supply air), and therefore, when it reaches the exhaust duct, it is relatively cold. Because the air in this duct is cold and the duct passes through conditioned space, the exhaust duct is insulated. Similar to the intake duct, some heat from the conditioned space 
is transferred through this insulation into the cold air flowing out through the exhaust duct. This warms the exhaust air flowing into the outside environment and increases the heat loss associated with ventilation. This effectively lowers the heat recovery efficiency of the HRV system. The heat that is transferred from the conditioned space into the cold air through the insulation of the duct must be resupplied from the building heat sources, which leads to an increase in the building energy consumption.

The purpose of our research published in this paper was to derive a mathematical model for the overall heat recovery efficiency of HRV systems that accounts for the intake and exhaust ducts and to validate this model using real-life data. The goal of publishing this mathematical model was to aid in planning the HRV intake and exhaust ducts in terms of their lengths and insulating values, as well as provide a tool to more accurately calculate the heat loss that is associated with ventilation in HRV-equipped buildings. For example, some building energy simulation tools do not explicitly have the option of accounting for the impacts of the HRV intake and exhaust ducts and simply just ask for the heat recovery efficiency of the HRV. In these situations, using the overall HRV system heat recovery efficiency, as determined from the mathematical model published in this paper, will yield more accurate results than inputting the heat recovery efficiency of just the HRV unit itself.

\section{Materials and Methods}

\subsection{Deriving the Mathematical Model for Calculating the HRV System Heat Recovery Efficiency}

The mathematical model for calculating the heat recovery efficiency of the HRV system, which accounts for the impacts of the intake and exhaust ducts, is derived in the following paragraphs. In order to derive the model, an HRV unit placed in the conditioned space of a building and connected to the outside environment via insulated intake and exhaust ducts was considered (see Figure 1).

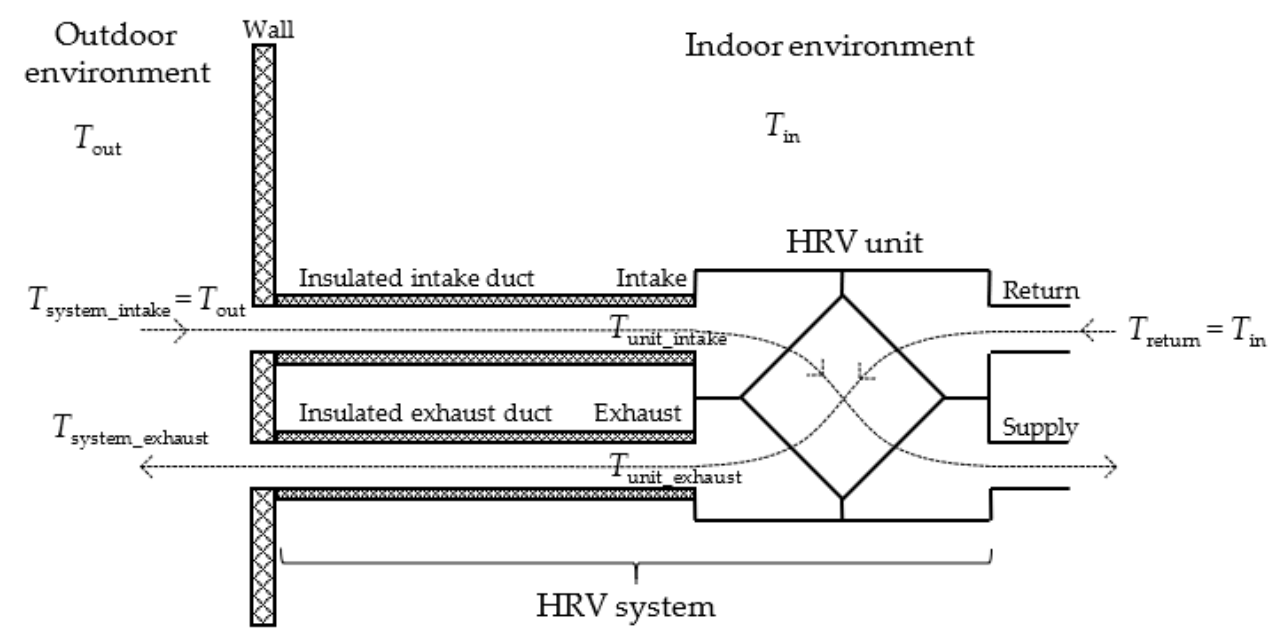

Figure 1. Conceptual drawing of the heat recovery ventilator (HRV) system. The HRV system consists of an HRV unit and insulated intake and exhaust ducts. See the Nomenclature section for the meanings of the shown variables.

In deriving the mathematical model, it was assumed that the HRV system has a balanced airflow, which means that the airflow rate for the intake/supply airstream is the same as the airflow rate for the return/exhaust airstream. Another assumption was that the HRV system is perfectly sealed, which means there is no cross-leakage between the two airstreams inside the system and neither are there any casing nor duct leakages. Furthermore, steady-state conditions were assumed in the derivation of the model.

The mathematical model deals with the heat recovery efficiency of the HRV system, which is defined as follows:

$$
\eta_{\text {HRV_system }}=\frac{T_{\text {return }}-T_{\text {system_exhaust }}}{T_{\text {return }}-T_{\text {system_intake }}},
$$


where $\eta_{\text {HRV_system }}$ is the heat recovery efficiency of the HRV system, $T_{\text {return }}$ is the temperature of the air entering the return port of the HRV, $T_{\text {system_exhaust }}$ is the temperature of the air exhausted from the HRV system to the outside, and $T_{\text {system_intake }}$ is the temperature of the air at the intake of the HRV system (see Figure 1). Since the air entering the return port of the HRV is the indoor air and the air at the intake of the HRV system is the outdoor air, the denominator of the above formula is the temperature difference between the inside and outside. In the case of perfect heat recovery, the temperature of the air exhausted to the outside would equal the outdoor temperature, in which case, the numerator of the above formula would also be the temperature difference between the inside and outside, and the resulting value of the heat recovery efficiency of the HRV system would be $100 \%$. On the other hand, in the case of natural ventilation, the temperature of the air exhausted to the outside would equal the indoor temperature, which means the numerator of the above formula would equal zero and the resulting value of the heat recovery efficiency of the HRV system would be $0 \%$. These are the principles that the above definition is based on.

Analogous to the heat recovery efficiency of the HRV system, the heat recovery efficiency of the HRV unit is defined as follows:

$$
\eta_{\text {HRV_unit }}=\frac{T_{\text {return }}-T_{\text {unit_exhaust }}}{T_{\text {return }}-T_{\text {unit_intake }}},
$$

where $\eta_{\text {HRV_unit }}$ is the heat recovery efficiency of the HRV unit, $T_{\text {unit_exhaust }}$ is the temperature of the air exhausted from the HRV unit, and $T_{\text {unit_intake }}$ is the temperature of the air at the intake of the HRV unit (see Figure 1).

When the outside cold air enters the intake duct, it is warmed as it passes through the duct. This warming is due to heat conduction from the indoor environment through the duct's insulation; how much the air is warmed up can be derived as follows. A round duct was assumed, which means that the shape of the pocket of air that has the same temperature throughout its volume and that is traveling through the duct is a disk with an infinitesimal thickness. From the physical law of energy conservation, the amount of heat conducted through the insulation of the duct into this air disk must equal the increase in the heat content of this air disk:

$$
\frac{\mathrm{d} A\left(T_{\text {in }}-T\right)}{R_{\text {intake }}} \mathrm{d} t=\mathrm{d} m c_{p} \mathrm{~d} T,
$$

where $\mathrm{d} A$ is the infinitesimal contact area between the duct and the air disk, $T_{\text {in }}$ is the indoor temperature, $T$ is the temperature of the air disk as a function of time as it travels through the duct, $R_{\text {intake }}$ is the thermal insulance (also called R-value) of the insulation of the intake duct, $\mathrm{d} t$ is an infinitesimal increment in time, $\mathrm{d} m$ is the mass of the air disk with an infinitesimal thickness, $c_{p}$ is the specific heat capacity of air, and $\mathrm{d} T$ is the infinitesimal increase in the temperature of the air disk over the period of $\mathrm{d} t$.

Solving the above differential equation (Equation 3) yields the following result:

$$
T(t)=T_{\text {in }}-\left(T_{\text {in }}-T_{\text {out }}\right) \mathrm{e}^{-\frac{4}{R_{\text {intake }} \rho D_{\text {intake }} c_{p}}},
$$

where $T_{\text {out }}$ is the outdoor temperature, $\rho$ is the density of air, and $D_{\text {intake }}$ is the inside diameter of the intake duct. It should be clarified that in solving the differential equation, the density of air and the specific heat capacity of air were assumed to be constant. This is because their slight dependences on the temperature were considered negligible for the purposes of this research.

Knowing the airflow rate and parameters of the intake duct, the time it takes for the air to pass through the duct can be calculated. Plugging this time into Equation 4, the 
temperature of the air at the end of the intake duct (which means at the intake of the HRV unit) can be calculated:

$$
T_{\text {unit_intake }}=T_{\text {in }}-\left(T_{\text {in }}-T_{\text {out }}\right) \mathrm{e}^{-\frac{\pi D_{\text {intake }} l_{\text {intake }}}{R_{\text {intake }} \rho_{p} Q}},
$$

where $T_{\text {unit_intake }}$ is the air temperature at the intake of the HRV unit, $l_{\text {intake }}$ is the length of the intake duct, and $Q$ is the volumetric airflow rate.

Knowing the air temperature at the intake of the HRV unit and the heat recovery efficiency of the unit, the air temperature at the exhaust of the HRV unit can be calculated by utilizing the definition of the heat recovery efficiency of the HRV unit (Equation (2)), as follows:

$$
T_{\text {unit_exhaust }}=T_{\text {in }}-\left(T_{\text {in }}-T_{\text {unit_intake }}\right) \eta_{\text {HRV_unit }}
$$

where $T_{\text {unit_exhaust }}$ is the air temperature at the exhaust of the HRV unit.

The air temperature at the HRV unit exhaust is the air temperature at the beginning of the exhaust duct. As the air is traveling through the duct, it is warmed. This warming is due to heat conduction from the indoor environment through the duct's insulation. The temperature change of the air can be derived in a similar manner to how it was derived for the intake duct. The result is as follows:

$$
T_{\text {system_exhaust }}=T_{\text {in }}-\left(T_{\text {in }}-T_{\text {unit_exhaust }}\right) \mathrm{e}^{-\frac{\pi D_{\text {exhaust }} l_{\text {exhaust }}}{R_{\text {exhaust }} \rho_{p} p^{Q}}},
$$

where $T_{\text {system_exhaust }}$ is the air temperature at the exhaust of the HRV system (the outlet of the exhaust duct), $D_{\text {exhaust }}$ is the inside diameter of the exhaust duct, $l_{\text {exhaust }}$ is the length of the exhaust duct, and $R_{\text {exhaust }}$ is the thermal insulance of the insulation of the exhaust duct.

Knowing the air temperature at the exhaust of the HRV system, the heat recovery efficiency of the HRV system can be calculated by utilizing its definition (Equation (1)), as follows:

$$
\eta_{\text {HRV_system }}=\frac{T_{\text {in }}-T_{\text {system_exhaust }}}{T_{\text {in }}-T_{\text {out }}} .
$$

Equations (5)-(8) are the mathematical model that allows for the calculation of the heat recovery efficiency of an HRV system from the heat recovery efficiency of the HRV unit, its airflow rate, the parameters of the intake and exhaust ducts, and the indoor and outdoor temperatures. Equations (5)-(8) can be combined into one. The resulting expression is for the heat recovery efficiency of the HRV system as a function of the heat recovery efficiency of the HRV unit, airflow rate, and parameters of the intake and exhaust ducts; the indoor and outdoor temperatures are not needed because they cancel out (see Results section). Equations (5)-(8), where the indoor and outdoor temperatures are needed, are still useful on their own for validating the model with real in situ temperature data.

\subsection{Validating the Mathematical Model with Real-Life Data}

Data from an HRV installation at the Cold Climate Housing Research Center in Fairbanks, Alaska, was utilized for the validation of the mathematical model. The HRV

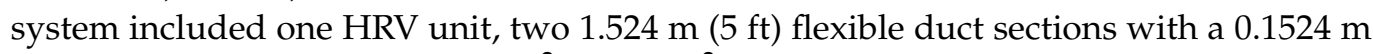
(6 in) inside diameter and a $1.409 \mathrm{~m}^{2} \mathrm{~K} / \mathrm{W}\left(8 \mathrm{ft}^{2} \mathrm{~h}^{\circ} \mathrm{F} / \mathrm{Btu}\right)$ insulance (one each for the intake and exhaust), and a combined exterior intake/exhaust port, which is an accessory that combines the system intake and exhaust ports into a single wall penetration. The airflow rate of this system was $0.02265 \mathrm{~m}^{3} / \mathrm{s}\left(48 \mathrm{ft}^{3} / \mathrm{min}\right)$.

Because a combined exterior intake/exhaust port was used in the installation, the temperature measured at the connection between the port and the intake duct was substituted for the outdoor temperature (system intake). This was necessary because the installation of the combined exterior intake/exhaust port was unconventional (a part of a different research project) and a significant amount of heat transfer was occurring within the port. To 
maintain consistency, the system exhaust temperature was measured at the corresponding connection of the exhaust duct.

Data were collected in $10 \mathrm{~s}$ intervals using PS103J2 thermistors (Littlefuse, Chicago, IL, USA) and a CR1000 datalogger (Campbell Scientific, Logan, UT, USA) and converted into one-minute averages. The air temperature was measured at all four HRV ports and at the exterior end of each duct. The installation was monitored between December 2019 and March 2020. From this data, sections were selected for the model validation. Of particular interest were sections with large differentials between the outdoor and indoor temperature. For these sections, the signal-to-noise ratio was large, and thus, the influence of noise on the results was minimized. Note that since the data for validation must include steady-state operation only (no defrost cycles), periods when temperatures were below the HRV unit defrost activation temperature were excluded. This resulted in selecting two data sections for the model validation: one section was collected on 19 February from 00:01 to 02:57 local time and the other on 20 February from 10:54 to 17:31 local time.

\section{Results}

\subsection{Mathematical Model for Calculating the HRV System Heat Recovery Efficiency}

Equations (5)-(8) represent the mathematical model for calculating the heat recovery efficiency of an HRV system, as well as certain temperatures throughout the system. However, one of the goals of our research was to derive a single mathematical expression for the heat recovery efficiency of the HRV system as a function of the heat recovery efficiency of the HRV unit, airflow rate, and parameters of the intake and exhaust ducts. This was achieved by combining Equations (5)-(8) into a single formula. The resulting expression is as follows:

$$
\eta_{\text {HRV_system }}=\eta_{\text {HRV_unit }} \mathrm{e}^{-\frac{\pi}{\rho c_{p} Q}\left(\frac{D_{\text {intake }} l_{\text {intake }}}{R_{\text {intake }}}+\frac{D_{\text {exhaust }} l_{\text {exhaust }}}{R_{\text {exhaust }}}\right)} .
$$

The intake and exhaust ducts are often of the same type, which means they have the same diameter and thermal insulance. For those scenarios, Equation 9 can be further simplified:

$$
\eta_{\text {HRV_system }}=\eta_{\text {HRV_unit }} \mathrm{e}^{-\frac{\pi D\left(l_{\text {intake }}+l_{\text {exhaust }}\right)}{\rho c_{p} Q R}},
$$

where $D=D_{\text {intake }}=D_{\text {exhaust }}$ is the inside diameter of the intake/exhaust duct and $R=R_{\text {intake }}=R_{\text {exhaust }}$ is the thermal insulance of the intake/exhaust duct.

In order to study the impact of the parameters of the intake and exhaust ducts on the overall heat recovery efficiency of HRV systems, the plot of Equation (10) for different thermal insulance values is shown in Figure 2. It should be noted that where specific numbers are presented in this article, if the density of air and the specific heat capacity of air were utilized in calculating those numbers, the values of $1.2 \mathrm{~kg} / \mathrm{m}^{3}\left(0.075 \mathrm{lb} / \mathrm{ft}^{3}\right)$ for the density of air and $1006 \mathrm{~J} / \mathrm{kgK}\left(0.2403 \mathrm{Btu} / \mathrm{lb}^{\circ} \mathrm{F}\right)$ for the specific heat capacity of air were used.

To facilitate the use of the mathematical model derived herein by a broader audience, Equations (5)-(8), as well as Equation (10), were implemented as an online calculator [14].

\subsection{Model Validation}

The model was evaluated by comparing the predicted HRV system heat recovery efficiency with the actual HRV system heat recovery efficiency derived from the measured temperatures (using Equation (8)). Using the heat recovery efficiency of the HRV unit, the airflow rate, and the reported system parameters as the inputs for the mathematical model, the predicted HRV system heat recovery efficiency could be calculated (using Equation (10)). In this calculation, the HRV unit heat recovery efficiency values were determined from their definition (Equation (2)) rather than the manufacturer specified value. This was because the aim of this research was to evaluate the mathematical model for the impacts of the intake/exhaust ducts, not the HRV unit manufacturer's claims. See Table 1 for the results 
of this evaluation from two sections of data collected in a real-life HRV installation (see

Section 2.2 for details).

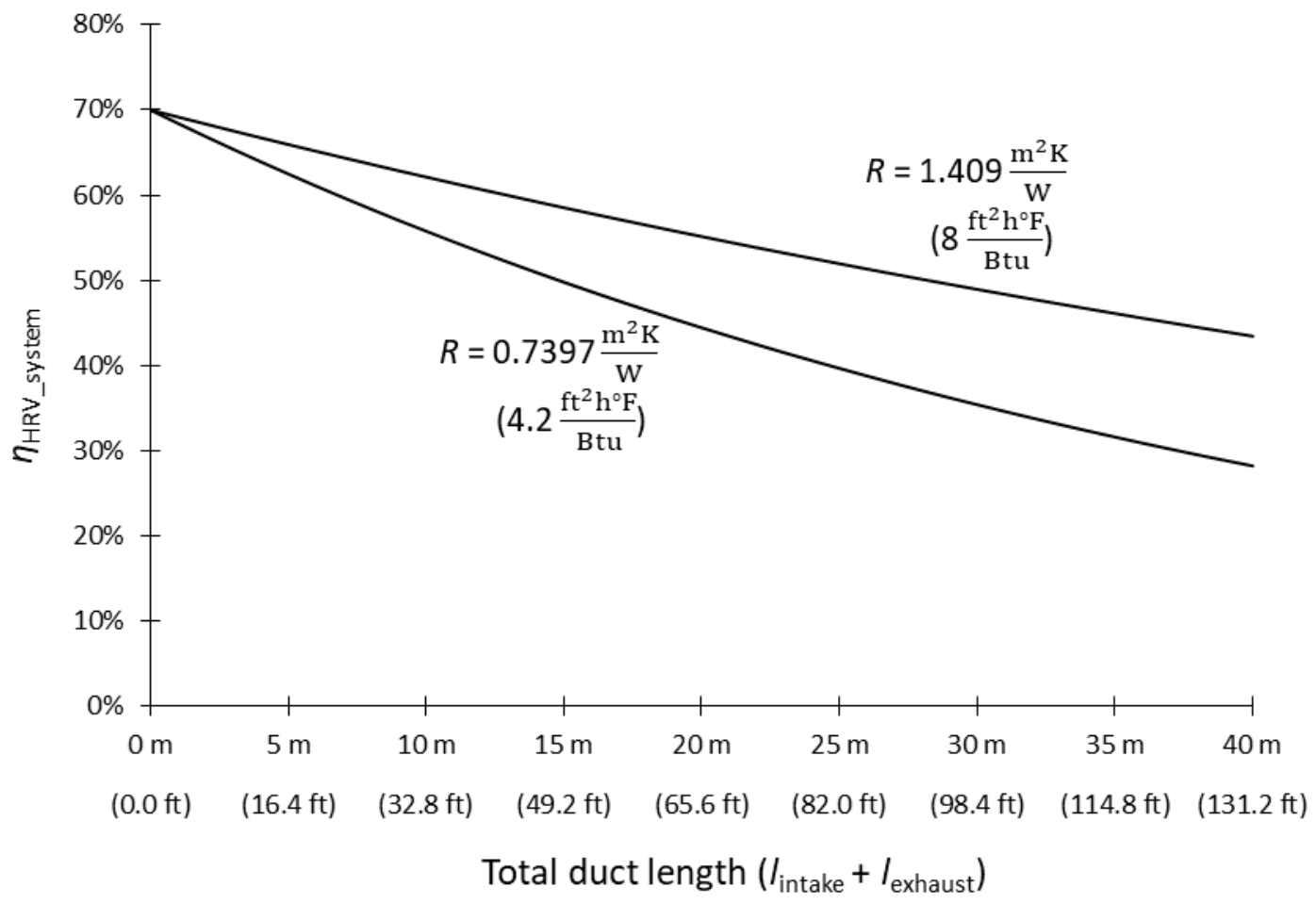

Figure 2. Overall heat recovery efficiency of an HRV system as a function of the total duct length (intake + exhaust) for different thermal insulance values. A duct inside diameter of $0.1524 \mathrm{~m}(6 \mathrm{in})$, an airflow rate of $0.02360 \mathrm{~m}^{3} / \mathrm{s}\left(50 \mathrm{ft}^{3} / \mathrm{min}\right)$, and a heat recovery efficiency of the HRV unit of $70 \%$ were assumed.

Table 1. Comparison between the measured and model-predicted data.

\begin{tabular}{|c|c|c|c|}
\hline Quantity & Specification & $02 / 19 / 2020$ & $02 / 20 / 2020$ \\
\hline$T_{\text {out }}$ (same as $\left.T_{\text {system_intake }}\right)$ & & $-9.97^{\circ} \mathrm{C}$ & $-7.69^{\circ} \mathrm{C}$ \\
\hline$T_{\text {unit_intake }}$ & & $-9.39^{\circ} \mathrm{C}$ & $-7.16^{\circ} \mathrm{C}$ \\
\hline$T_{\text {in }}$ (same as $\left.T_{\text {return }}\right)$ & & $9.87^{\circ} \mathrm{C}$ & $10.83^{\circ} \mathrm{C}$ \\
\hline$T_{\text {unit_exhaust }}$ & & $-2.33^{\circ} \mathrm{C}$ & $-1.13^{\circ} \mathrm{C}$ \\
\hline$T_{\text {system_exhaust }}$ & & $-2.13^{\circ} \mathrm{C}$ & $-0.94{ }^{\circ} \mathrm{C}$ \\
\hline$\eta_{\text {HRV_unit }}$ & & $63.37 \%$ & $66.51 \%$ \\
\hline \multirow{2}{*}{$\eta_{\text {HRV_system }}$} & Actual & $60.50 \%$ & $63.55 \%$ \\
\hline & Predicted & $61.02 \%$ & $64.04 \%$ \\
\hline \multirow{2}{*}{$\begin{array}{l}\eta_{\text {HRV_unit }}-\eta_{\text {HRV_system }} \\
\text { The decrease in heat recovery efficiency } \\
\text { resulting from the ducts. }\end{array}$} & Actual & $2.87 \%$ & $2.95 \%$ \\
\hline & Predicted & $2.35 \%$ & $2.48 \%$ \\
\hline $\begin{array}{c}\left(1-\frac{\left(\eta_{\text {HRV_unit }}-\eta_{\text {HRV_system }}\right)}{\left(\eta_{\text {HRV_unit }}-\eta_{\text {HRV_system }}\right)_{\text {Actual }}}\right) \times 100 \% \\
\text { The relative error of the predicted } \\
\text { decrease in heat recovery efficiency } \\
\text { resulting from the ducts. }\end{array}$ & & $18.06 \%$ & $16.14 \%$ \\
\hline
\end{tabular}

The temperatures shown were measured temperature averages for the two selected data sections. The system heat recovery efficiencies were calculated using duct lengths of $1.524 \mathrm{~m}(5 \mathrm{ft})$ for each of the ducts, duct inside diameters of $0.1524 \mathrm{~m}(6 \mathrm{in})$, a thermal insulance of $1.409 \mathrm{~m}^{2} \mathrm{~K} / \mathrm{W}\left(8 \mathrm{ft}^{2} \mathrm{~h}^{\circ} \mathrm{F} / \mathrm{Btu}\right)$, and a volumetric airflow rate of $0.02265 \mathrm{~m}^{3} / \mathrm{s}\left(48 \mathrm{ft}^{3} / \mathrm{min}\right)$. 


\section{Discussion}

As expected, the heat recovery efficiency of the HRV system (consisting of an HRV unit and intake/exhaust ducts) is lower than the heat recovery efficiency of the HRV unit alone. This was shown via theoretical calculations and real-life measurements. The graph in Figure 2, which is based on theoretical calculations, shows that the decrease in heat recovery efficiency is minimal with short and highly insulated intake/exhaust ducts, but can be very significant with very long and less insulated ducts. For example, with a $40 \mathrm{~m}$ (131.2 ft) combined duct length (intake + exhaust), $0.1524 \mathrm{~m}$ (6 in) duct inside diameter, $0.7397 \mathrm{~m}^{2} \mathrm{~K} / \mathrm{W}\left(4.2 \mathrm{ft}^{2} \mathrm{~h}^{\circ} \mathrm{F} / \mathrm{Btu}\right)$ thermal insulance of the ducts, and $0.02360 \mathrm{~m}^{3} / \mathrm{s}$ $\left(50 \mathrm{ft}^{3} / \mathrm{min}\right.$ ) airflow rate, the system heat recovery efficiency is less than $30 \%$, despite the heat recovery efficiency of the HRV unit being $70 \%$. These numbers show that using very long and less insulated ducts largely defeats the purpose of using an HRV. These numbers also show that neglecting to account for the impact of intake and exhaust ducts can result in a significant error when calculating the heat loss and corresponding energy costs. For example, a typical residence in Fairbanks, Alaska, that is properly ventilated and using no heat recovery is estimated to spend about 690 USD annually in heating costs to cover the heat loss associated with ventilation [12]. Using a simplified analysis, an HRV system with very long and less insulated intake/exhaust ducts and a $30 \%$ overall heat recovery efficiency would save about $30 \%$ of the 690 USD, which means about 210 USD annually. However, if the impact of the intake and exhaust ducts is neglected and only the $70 \%$ heat recovery efficiency of the HRV unit alone is used in these calculations, the calculated savings would be about 480 USD annually, which means an error of about 270 USD annually. These numbers show that taking the impact of the intake and exhaust ducts into consideration can be very important. The model developed in our research provides a tool to do that.

The mathematical model for the system heat recovery efficiency was validated using real-life data. As seen in Table 1, the predicted decrease in heat recovery efficiency due to the ducts was in reasonable agreement (relative error within 20\%) with the real-life measurements. The predicted decrease was slightly lower than the actual decrease, but this was likely due to inaccuracies in the measurement system. These inaccuracies are explained further in the paragraph below. However, this real-life installation had relatively short and relatively well-insulated ducts. Our recommendation for future research is to study additional real-life installations and validate the mathematical model across a wide range of situations.

It should also be pointed out that the relatively short and relatively well-insulated ducts affected the ability to accurately validate the mathematical model because the temperature increase of the air as it flowed through the short sections of ducts was relatively small in relation to the accuracy of the temperature measurement system. For example, when looking at the 19 February 2020 data section in Table 1, the theoretical temperature rise in the intake duct (if calculated using Equation 5) would be about $36 \%$ smaller than the measured value. On the other hand, the theoretical temperature rise in the exhaust duct (if calculated using Equation 7) would be about 13\% greater than measured. A side-by-side test of the temperature sensors in an ice bath was performed, with the temperature sensors connected to the datalogger in the same way as in the HRV test; the difference in the temperature measurements was minimal and unable to explain the $36 \%$ and $13 \%$ discrepancies described above. However, it should be explained that the temperature measurements in the ducts were performed by inserting a single temperature sensor in each location. However, the temperature of the air throughout the duct cross-section was not necessarily perfectly uniform. Using a grid of temperature sensors would likely provide better results than just using one. Our recommendation for future research is to include systems with very long and less insulated ducts for the real-life measurements, not only to help validate the model in a wide range of situations (as mentioned in the recommendation in the above paragraph) but also to allow for more accurate verification. This would mean that the 
temperature rise in the ducts would be large compared to the accuracy of the temperature measurement system.

The research presented in this paper also has implications regarding innovations in HRV systems. It underscores the need for innovations in all HRV system components, not just the HRV unit itself, if maximum recovery efficiencies are to be achieved. One such innovation is currently happening in the area of combined exterior intake/exhaust ports, which combine the system intake and exhaust ports into a single wall penetration [15]. Utilizing a combined intake/exhaust port, aside from practical advantages, can shorten the length of the intake and exhaust ducts and increase the overall heat recovery efficiency of the HRV system. The mathematical model developed in our research provides a tool to consider the impacts on the overall heat recovery efficiency during the innovation process.

\section{Conclusions}

A mathematical model was derived that allows for calculating the heat recovery efficiency of an HRV system using the heat recovery efficiency of the HRV unit, the airflow rate, and the parameters of the intake and exhaust ducts. It was shown that in typical situations, when the intake and exhaust ducts are of the same type, the heat recovery efficiency of an HRV system can be calculated using a relatively simple analytical expression. This expression allows for the study of the impact of intake and exhaust ducts on the heat recovery efficiency of the system and aids in planning the parameters of $\mathrm{HRV}$ installations. It also allows for the conversion of heat recovery efficiency values of the HRV unit given by the manufacturer or testing laboratory into a more realistic value (representing the whole system) to be used for calculating the heat loss associated with ventilation. It was shown that this conversion is especially important for systems with very long and less insulated intake/exhaust ducts, where the overall heat recovery efficiency of the system can be less than $30 \%$, despite using an HRV unit with a heat recovery efficiency of $70 \%$. The model was implemented online to facilitate its use by a broader audience [14]. One of the ways this calculator is expected to be used is to supplement building energy simulation tools that do not explicitly allow for the accounting of intake and exhaust ducts and simply require the HRV heat recovery efficiency as an input. In these situations, the user can first input the heat recovery efficiency of the HRV unit, airflow rate, and duct parameters into this calculator, and then enter the resulting heat recovery efficiency of the HRV system into the building energy simulation tool. The mathematical model was validated using real-life data. The results suggest that it can meaningfully contribute to improving energy-related calculations involving HRV systems, but more field studies are needed to verify the accuracy of the model in a wide range of applications.

Author Contributions: Conceptualization, T.M., C.D., and R.G.-S.; methodology, T.M., R.B., C.D., and R.G.-S.; validation, T.M. and R.B.; formal analysis, T.M. and R.B.; investigation, R.B. and C.D.; resources, T.M., C.D., and R.G.-S.; data curation, R.B.; writing-original draft preparation, T.M. and R.B.; writing-review and editing, T.M., R.B., C.D., R.G.-S., and J.K.; visualization, T.M. and R.B.; supervision, J.K.; project administration, T.M., C.D., and J.K.; funding acquisition, J.K. All authors have read and agreed to the published version of the manuscript.

Funding: This research was funded by the U.S. Army Engineer Research and Development Center (U.S. Army Program 633734T1500, Military Engineering Technology Demonstration), and the U.S. Navy Office of Naval Research.

Acknowledgments: The authors thank Qwerty Mackey and Haley Nelson with the Cold Climate Housing Research Center/National Renewable Energy Laboratory for their valuable contributions to this project. The authors also thank Ron Johnson, Professor Emeritus at the University of Alaska Fairbanks, for his valuable input.

Conflicts of Interest: The authors declare no conflict of interest. 


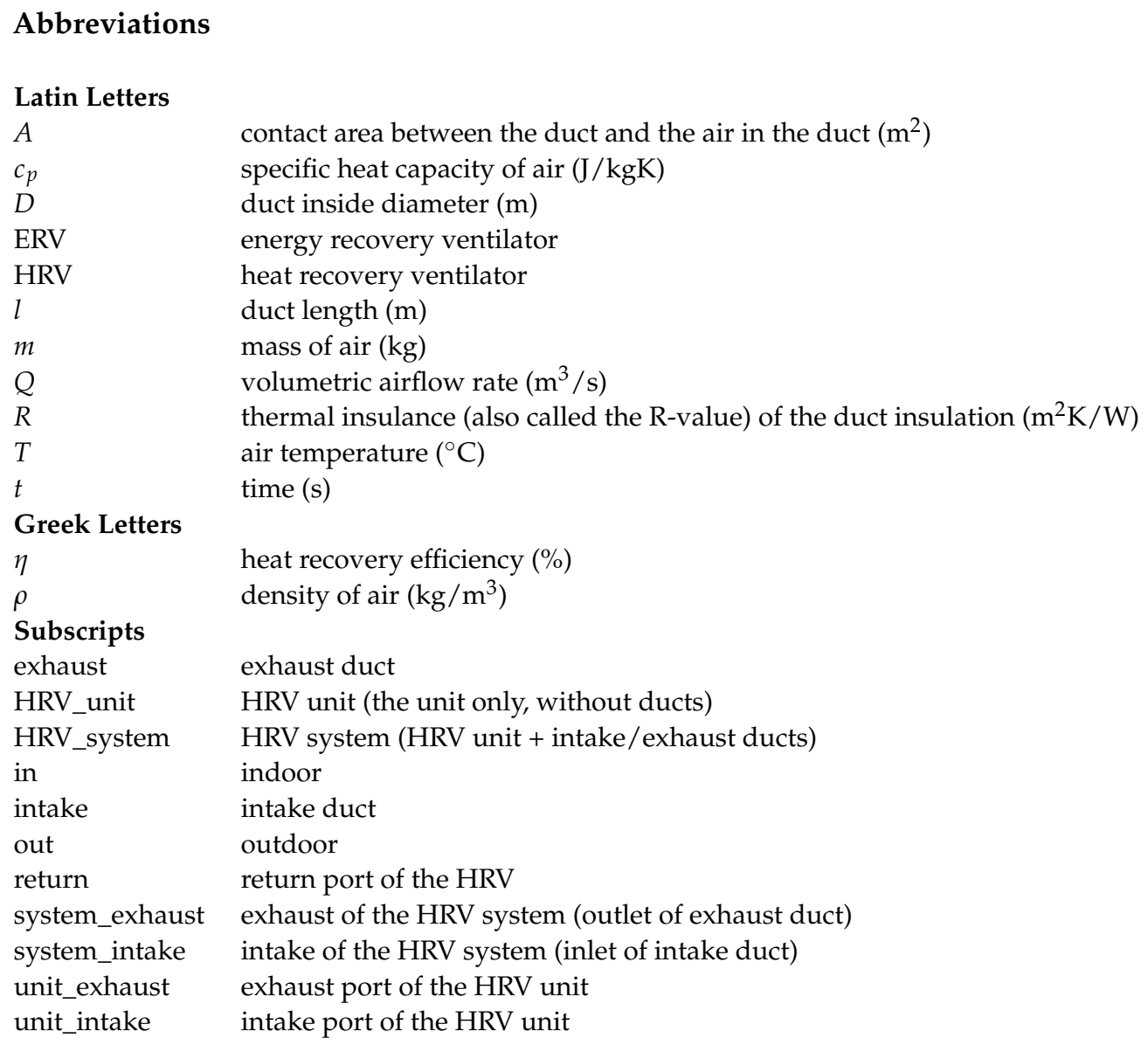

\section{References}

1. Cao, X.; Dai, X.; Liu, J. Building energy-consumption status worldwide and the state-of-the-art technologies for zero-energy buildings during the past decade. Energy Build. 2016, 128, 198-213. [CrossRef]

2. Ristinen, R.; Kraushaar, J.; Brack, J. Energy and the Environment, 3rd ed.; Wiley: Hoboken, NJ, USA, 2016.

3. MacKay, D. Sustainable Energy —Without the Hot Air; UIT Cambridge: Cambridge, UK, 2009.

4. Arruda, G. Renewable Energy for the Arctic-New Perspectives; Routledge: Abingdon, UK, 2019.

5. Schild, P.; Brunsell, J. Accurate Performance Testing of Residential Heat Recovery Units. Available online: https://www.aivc.org/ sites/default/files/members_area/medias/pdf/Conf/2003/2003069-Brunsell.pdf (accessed on 23 July 2020).

6. Bao, L.; Wang, J.; Yang, H. Investigation on the performance of a heat recovery ventilator in different climate regions in China. Energy 2016, 104, 85-98. [CrossRef]

7. Canadian Standards Association. C439-09 (Reaffirmed 2014): Standard Laboratory Methods of Test for Rating the Performance of Heat/Energy-Recovery Ventilators; Canadian Standards Association: Mississauga, ON, Canada, 2014.

8. Berquist, J.; Banister, C.; Krys, D. Performance of a Heat Recovery Ventilation System in the Canadian Arctic. Available online: https:/ / www.aivc.org/sites/default/files/D1_S3B-01.pdf (accessed on 23 July 2020).

9. Garber-Slaght, R.; Stevens, V.; Madden, D. Energy Recovery Ventilators in Cold Climates. 2014. Available online: http: / / cchrc.org/media/ERV_ColdClimates.pdf (accessed on 28 July 2020).

10. Persily, A. Evaluation of an air-to-air heat exchanger. Environ. Int. 1982, 8, 453-459. [CrossRef]

11. Grunau, B.; Craven, C. Zehnder Comfoair 350: Evaluation for use in a cold climate. 2015. Available online: http://cchrc.org/ media/HRV_FrostProtectionReport.pdf (accessed on 24 July 2020).

12. Marsik, T.; Johnson, R. Use of Simulink to evaluate the air-quality and energy performance of HRV-equipped residences in Fairbanks, Alaska. Energy Build. 2008, 40, 1605-1613. [CrossRef]

13. Carrié, F.; Leprince, V. Impact of Ductwork Airtightness and Conduction Losses on Heat Recovery Efficiency. In Proceedings of the Sixth International BUILDAIR Symposium on Building and Ductwork Airtightness, Berlin, Germany, 6 May 2011; Available online: https:/ / www.researchgate.net/publication/303881479_Impact_of_ductwork_airtightness_and_conduction_losses_on_ heat_recovery_efficiency (accessed on 24 July 2020).

14. HRV System Recovery Efficiency Calculator. Available online: http://hrvcalc.cchrc.org/ (accessed on 28 August 2020).

15. Heat Recovery Ventilation Idea Wins Innovation Prize. Available online: https://news.uaf.edu/heat-recovery-ventilation-ideawins-innovation-prize/ (accessed on 5 December 2020). 